\title{
Existential Ludology and Peter Wessel Zapffe
}

Stefano Gualeni \& Daniel Vella

In Navarro-Remesal, V., and Pérez-Latorre, O., Perspectives on the European Videogame (Amsterdam: Amsterdam University Press), pp. 175-192.

\begin{abstract}
:
A relatively common approach in game studies understands gameworlds as constituting an existential situation for the player. Taking that stance, which is rooted in the European philosophical tradition of Existentialism, in this chapter we investigate the relationships and similarities between our existence within and without gameworlds. To do so, we first provide a review of existing literature in 'existential ludology' - work in game studies which considers our engagement with gameworlds from an existential perspective. In the second part of the chapter, we then engage with some of the most notable ideas of the Norwegian philosopher Peter Wessel Zapffe. Zapffe understood human life as inherently meaningless and identified four ways in which human beings typically protect themselves from the existential panic that accompanies the awareness of that meaninglessness: isolation, anchoring, distraction, and sublimation. These four categories are used as the foundation for an examination of gameworlds as technologies for repressing existential panic.
\end{abstract}

\section{Keywords:}

Existentialism, ludology, Peter Wessel Zapffe, isolation, anchoring, distraction, sublimation

\section{Authors bio:}

Stefano Gualeni (Ph.D.) is a philosopher who designs games. He is an Associate Professor at the Institute of Digital Games, University of Malta, and Visiting Professor at the Laguna College of Art and Design in Laguna Beach, California, USA.

Daniel Vella (Ph.D.) is a Senior Lecturer at the Institute of Digital Games, University of Malta. $\mathrm{He}$ is a member of the steering committee for the Game Philosophy Network and is also active as a writer and narrative designer for board games.

$$
* * *
$$

One would be pointing out the obvious to note that digital games are produced and played within specific sociocultural contexts, and that, both as technological artefacts and as 
cultural texts, they will inevitably reflect the ideologies and worldviews that structure those contexts - and can only be understood within, and in relation to, those contexts. Accordingly, if we aspire to understand the existential significance of digital games, we should always approach them in relation to the historical and sociocultural contexts within which they are developed, understanding them as products and reflections of this context.

In this chapter, we will consider digital games as products of the system of thought which emerged with the Industrial revolution in eighteenth-century Europe, and which - as a techno-socio-cultural organization of the world - continues to hold sway across what we refer to as 'the West'. The interlinked, and mutually determining, elements of this organization include industrially-motivated technological development, a capitalist economy, and an individualist notion of subjectivity and selfhood that finds its first thorough articulation in postKantian Romanticism. As products of this episteme, it is hardly surprising that digital games reflect these elements of their context. Not only are they technological products produced and consumed within a capitalist economy, but they also reproduce, and are structured on the assumption of, the liberal notion of the self that has dominated Western thinking in the era of capitalism (Möring and Leino, 2016).

Given this insight, it is hardly surprising that a distinct tradition has emerged within game studies which, under the label of 'existential ludology', has theorized games through the lens of existentialist philosophy - drawing heavily on the work of the philosophers Martin Heidegger, Jean-Paul Sartre and Maurice Merleau-Ponty in particular. After all, this philosophical tradition - at the risk of grossly simplifying matters - emphasizes the individuality of the human being, foregrounding notions like freedom and responsibility to anchor meaning within one's own individual being and existence. Existentialism, as such, is both a product of and a response to the malaise generated by the organization of the world that has held sway over Europe and the West since the Industrial Revolution.

In the first section of this chapter, we shall provide an overview of existing work in the field of existential ludology, focusing, in particular, on the work of Matthew Thomas Payne (2008), Olli Tapio Leino (2009; 2010), Daniel Vella (2015; 2016a), and Marta Matylda Kania (2017). We shall demonstrate how what these various approaches have in common is their drawing on existential philosophy to arrive at the understanding that the player's being in (and towards) digital game worlds operates according to existential mechanisms analogous to those by which we engage with the actual world.

On the basis of this overview, we will then move on, in the second section of this chapter, to looking at digital game play through the lens of the ideas of the lesser-known 
existential philosopher Peter Wessel Zapffe $(1933 ; 1941)$. Our aim in doing so will be to answer the question: what is the existential function of digital game play? To put it differently: as subjects of a Western, individualistic, capitalist order, and living in a relation to the world that is determined by that order, what do we get out of digital games, and why are we drawn to them?

\section{Existential Ludology}

A significant current in digital game studies examines digital games, and players' experience of gameworlds through the lens of this philosophical tradition. In 2008, Matthew Thomas Payne proposed the term 'existential ludology' to refer to the application of the lens of existential philosophy to the study of digital game experience: 'if existential phenomenology asks about the possibilities and meaningfulness of human action in the lived world, then existential ludology [...] asks similar questions about meaningful play in the virtual world' (2008, p. 622). In his formulation, such an approach leads to a method of game analysis that 'works by cataloguing numerous game-play experiences to forward meaningful statements about how particular games evidence recurrent and stable experiential structures' (ibid., p. 624). Implicit in Payne's approach is the claim that these experiential structures by which we engage with digital game worlds reflect those by which, as embodied human subjects, we engage with the actual world. As a result, existential-phenomenological concepts for theorizing experience can be brought to bear upon the study of player experience - as Payne adopts Maurice Merleau-Ponty's concept of the 'intentional arc', or reworks Jean-Paul Sartre's concept of 'reflective consciousness' into 'replay consciousness' (ibid., p. 631).

A similar assumption undergirds Olli Tapio Leino's existential approach to game play, which draws upon a primarily Sartrean framework. Like Payne, Leino adopts Sartre's notion of 'facticity' - the contingent domain of actuality that constitutes the individual's existential situation, and against which her freedom is measured. Leino discusses games as 'extended facticities' for the player (2010, p. 220), granting a domain of contingency supplementary to the actual world against which the player can build a subjective existence.

In relation to this extended facticity, he defines the 'gameplay condition' (2009, p. 12; 2010 , p. 101) as the condition of responsibility that is imposed upon the player. This condition of responsibility results from the fact that the game will factually uphold the results of the player's choices, granting these choices real consequences within the game as an experiential domain. As such, the facticity of the game is what renders possible the existential 'projects' - 
another term that Leino adopts from Sartre - around which the player can structure her in-game existence. At the same time, it is also what resists the realization of these projects, demanding active effort and work on the part of the player in the pursuit of her goals. To subject oneself to the gameplay condition, then, means to accept a measure of responsibility for one's own ingame being, on the basis of the fact that the game will concretely actualize the outcomes of the player's choices and actions - whether this means progressing to the next level or seeing a 'Game Over' screen.

Similarly indebted to the existential and phenomenological tradition is the notion of 'ludic subjectivity', which we have explored in our previous work (Vella 2015; 2016a). This attempt at theorizing the experiential structure of the player's subjective being-in-thegameworld centres on two interlinked notions. Firstly, the 'ludic subject-position' refers to the perceptual and existential standpoint that is formally established for the player in the gameworld - through, for instance, the capabilities and limitations the player is granted, the goals they are set or allowed to set for themselves, and so on (Vella 2015, pp. 266-289). Together, these situate the player in a particular position in relation to the game - a position of strength or of vulnerability, for example. This position, then, becomes the perspective from which the game is grasped as a meaningful world of experience. Secondly, the 'ludic subject' is the subjective existence the player plays out by engaging with the virtual world of the game from the standpoint of the ludic subject-position, taking shape through the player's choices and decisive actions (ibid.).

On the basis of the concepts of the gameplay condition and ludic subjectivity, Marta Matylda Kania develops two interrelated notions - the 'self-avatar' and the 'gameplay situation'. The former is defined as 'an emergent being situated within the gameworld, consisting of the player's existence and intentional acts, and the features of the avatar' (2017, p. 7). The gameplay situation, then, is the 'perceptual position of the self-avatar towards the gameworld' (ibid., p. 61) - in other words, the shape that the gameworld takes as an existential situation around the standpoint of the self-avatar.

In summary, all of these existing approaches agree that there is an existential dimension to our engagement with digital games. The underlying assumption shared by all of these approaches is highlighted by Sebastian Möring when he argues that 'existential phenomena are repeated in play, as if they were from a world in a world or a life in a life' $(2014$, p. 2). The common idea is that players adopt an in-game subjective existence - often, but not always, associated with the avatar or playable figure - and that, from the perspective of this existence, the gameworld appears as an existential situation, within which the player's in-game 
experiences and actions gain meaning in a manner analogous to the ways in which we find meaning in our everyday existence in the world.

In this chapter, we want to take this assumption as a starting point, and pursue a line of inquiry that goes in a slightly different direction. The question we wish to investigate is: if it is the case that, in digital game worlds, we play out a duplicate in miniature of the existential structures of our being-in-the-world, what is the existential value and appeal of doing so? In other words, when considered through the lens of existential philosophy, what is the significance of engaging with virtual game worlds?

In order to tackle this question, we have chosen to consider the existential significance of the experience of gameworlds through the ideas of the Norwegian philosopher Peter Wessel Zapffe. This move might invite the obvious initial question: why take, as our focus, a philosopher who occupies, at best, a minor position in the canon of existential philosophy, and to whom relatively little scholarly attention has been paid?

Turning that question upon itself, we would like to offer the lack of existing work on Zapffe in game studies (and the paucity of critical engagement with Zapffe's philosophical work in general) as our first justification in itself. Rather than reiterating the existing work we have just discussed, this focus on Zapffe allows this chapter to make a novel contribution to existential ludology.

Our second justification is that - as we aim to make apparent - Zapffe's work is uniquely positioned to serve as the foundation for an understanding of the existential significance of digital games within a wider existential conception of human being as a whole. We will focus on Zapffe's presentation, in his essay 'The Last Messiah,' of a clear fourfold categorization of concrete existential tools or coping strategies by which we deal with what he characterizes as the tragic meaninglessness of human existence. The presence of such a definite taxonomy of existential structures differentiates Zapffe's work from that of his fellow existentialists, who, generally speaking, do not offer such a functional systematisation.

In the remainder of this chapter, then, we shall argue that applying Zapffe's taxonomy of existential coping strategies to the practice of digital game play allows us to speak of digital games not simply as 'reflections' of our everyday existence, or as existential 'aids' in terms of their acting as venues for self-expression or self-discovery. Instead, we will consider the possibility of understanding digital games as technologies put in the service of addressing, or, at the least, mitigating, our existential anxieties.

\section{The Last Messiah}


Peter Wessel Zapffe (1899-1990) was a Norwegian philosopher and lawyer. The few works of his that are translated into English focus on the idea of the absurd, cosmic squander that is life in all its forms.

In his work, Zapffe presents humans as beings who aspire to meaning and purpose in a world that is irredeemably meaningless. A recurring theme in his writings is the paradoxical idea that 'man has longings and spiritual demands that reality cannot fulfil'. ' This perspective is central to Zapffe's notion of 'the tragic' and of his consideration of the human being as a 'tragic animal'. Of particular interest is the fact that, for Zapffe, the specific ways in which human existence can be considered tragic are not rooted in the fact that the human being is weak, petty, or particularly prone to suffering, but rather 'in its being too capable for its own good. In a way that might clash with the nominal use of 'tragedy', Zapffe did not associate the term with notions like violence, misery, or scarcity, but with the idea of excess.' (Gualeni \& Vella 20202, p. 78).

His perspectives on this topic were originally presented in the essay 'The Last Messiah' (1933) and further developed in his treatise 'On the Tragic' (1941). Zapffe's understanding of the tragic resonates with the one that can be encountered, for example, in Sophocles' Antigone. In the 'Ode to Man' (the first choral song of the Antigone, lines 332-383), Sophocles characterizes humans as inherently tragic beings precisely because of their exceptional capabilities: their adaptability, their inventiveness, and their quick intellect. These qualities, Sophocles continues, allow humanity to understand and face all kinds of situations, to adapt, thrive, and to bend the wills of animals and rivers to its needs. Ceaselessly, humans direct their remarkable skills 'now to destruction/now again to greatness' (lines 366-367). From his perspective, humanity is awesome in both senses of the word: at once wondrous and dreadful (see De Mul 2009).

Likewise, in Zapffe's 1933 essay 'The Last Messiah' the human being is regarded as 'a biological paradox, an abomination, an absurdity, an exaggeration of disastrous nature' (Zapffe 2004, part II). ${ }^{2}$ In it, Zapffe explicitly presents humanity as a mistake: the tragic result of nature

\footnotetext{
${ }^{1}$ This quote is taken from the 1990 documentary The philosopher Peter Wessel Zapffe in his 90th year, Original Films AS, Troms $\varnothing$, Norway.

${ }^{2}$ Zapffe further clarifies that, in front of human beings, '[...] all things chain together in causes and effects, and everything he wants to grasp dissolves before his testing thought' (Zapffe 2004, part II). Compare this passage to a similar one in Sophocles' Antigone, where human beings are presented as having taught themselves 'speech and thought, quick as the wind / and the mood and mind for law that rules the city [...] Man, the master, ingenious past all measures.' (Sophocles 1984, lines 395, 396, 406)
} 
having overshot its intended target: '[a] species had been armed too heavily', thereby becoming 'a menace to its own well-being'. (ibid.)

In which sense does he consider the human being a mistake and a threat to itself? Zapffe highlights what he considers a crucial, existential difference between human beings and beasts: whereas the suffering of beasts is self-confined (that is, limited to the individual experience of each beast), human beings can grasp the cosmic nature of the meaningless and endlesslyrepeating nightmare that is existence. Human beings alone are aware that struggle and suffering are ubiquitous, eternal, and purposeless, and it is this awareness that sets them apart from other animals. As a consequence, humanity finds itself in a constant state of existential panic.

If this is so, why, Zapffe asks, has humanity not long ago gone extinct 'during great epidemics of madness?' (Zapffe 2004, part III). Why do 'only a fairly minor number of individuals perish because they fail to endure the train of living - because cognition gives them more than they can carry?' (ibid.) His answer to these questions betrays a debt to the work of Sigmund Freud, arguing that most people simply learn to protect themselves by artificially suppressing their awareness of the absurdity of existence. In order to continue existing, Zapffe maintains, human beings constantly perform a 'repression of its damaging surplus of consciousness' (ibid.).

Seen from his perspective, states of depression or fits of madness are not understood as symptoms of a sick mind. Instead, they are indications that the mind's protective mechanisms are failing. In 'The Last Messiah', Zapffe grouped these protective mechanisms into four categories - isolation, anchoring, distraction, and sublimation - which can occur in every possible combination and often overlap with one another.

\section{Panic-repressing mechanisms in virtual environments}

As we summarized in the previous section, according to Zapffe, a constant panic characterizes life as experienced by human beings. The threat of existential despair is such a constant, overwhelming presence that the attempt to stave it off lies at the core of almost every human activity or pursuit.

Through a Zapffean lens, then, it would by no means be surprising - in fact, it would even be a foregone conclusion - to consider virtual environments as technologies that participate in controlling and mitigating our awareness of the meaninglessness of existence. 
This is possible, as we explained elsewhere, precisely because virtual subjectivity is a nested component of our actual subjectivity, and the two influence one another (Vella \& Gualeni, 2019; Gualeni \& Vella, 2020). On those theoretical premises, we observed that, in virtual worlds, those mechanisms aim to protect us from the awareness of both the meaninglessness of our actual existence and the meaninglessness of our virtual existence. With that panicrepressing purpose in mind, the creators of virtual environments typically design stimuli and motivations to keep us involved and psychologically invested in both worlds. Accordingly, we will address each of the four protective categories identified by Zapffe with a particular focus on how our relationships with gameworlds could be understood as participating in each.

\section{First category: Isolation}

With the term 'isolation', Zapffe indicates the ways in which we dismiss disturbing and destructive thoughts and feelings from our consciousness. In 'The Last Messiah', to exemplify the idea of isolation, Zapffe presents the cases of physicians and medical students who typically protect themselves from the tragic and disgusting aspects of their profession by adopting detached and technical stances towards their patients. Another example of the technique of isolation permeating our everyday life can be recognized in the fact that 'tact' (i.e. not confronting people with untimely reminders of sex, bodily functions, decay, and death) is considered a highly desirable social trait.

In terms of our existential relationship with virtual environments and digital games, the idea of isolation can be recognized to be obviously always at work. To play a digital game is, by definition, to willingly operate within a limited possibility horizon and to develop existential projects that are shaped by its affordances and by its narratives (Gualeni, 2019; Vella and Gualeni, 2019; Gualeni \& Vella, 2020). The re-framing (and even the practical removal) of the disgusting and tragic dimensions of existence is, thus, one of the defining qualities of our experiences with games in general. For example, one's death is commonly presented in digital games as a rather trivial inconvenience, a nuisance rather than a tragic event (Mukherjee 2009; Kirkpatrick 2011). With very rare exceptions ${ }^{3}$, our avatars do not age in virtual environments

\footnotetext{
${ }^{3}$ Apart from some experimental, independent games such as Is it Time? (Fraina 2010), the only counter-example we are aware of in a major commercial game is the role-playing game Fable (Lionhead Studios 2004). Even in Fable, however, disturbing thoughts are very much isolated from gameworlds: the player-character's age is capped at 65, and aging has only a cosmetic effect, with no impact upon the player-character's physical or mental abilities. It is also striking that the game's sequels stepped back from even this sanitized version of aging, with the feature being completely absent by the time of Fable III (Lionhead Studios 2011).
} 
- instead, we are presented with a fantasy of incessant self-improvement, in which our in-game selves can accumulate experiences indefinitely, growing ever stronger and more capable without the shadow of the inevitability of decline, senility, and mortality. Similarly, toilets and the use of toilets are, in the great majority of cases, tactfully removed from virtual environments.

In other words, gameworlds typically present us with 'sanitized' versions of the world, from which potentially upsetting reminders of the banality and futility of human existence have been excised.

\section{Second category: Anchoring}

In 'The Last Messiah', Zapffe describes societies as systems bound together by basic cultural ideas and collective values that are, for the most part, inherited from previous generations. He calls these ideas and values 'anchorings', as they can be understood as the fixed foundations which one's individual existence builds upon. Though this tends to be an unconsciously performed operation, the ways in which we adopt anchorings can also happen in a conscious manner. For example, when someone explicitly sets goals for oneself, or when deliberately adopting a certain rule of conduct (for instance, a professional deontology). One might, for instance, anchor one's existence in the project of progressing in one's career, or in the goal of raising a family, writing a great novel, or achieving a perfect physique.

Anchorings provide us with a sense of meaning and stability, protecting us from unsettling existential realizations concerning the meaninglessness of existence. According to Zapffe, we love our anchorings for the safety they offer, but at the same time we resent them for the ways in which they limit our freedom (Zapffe 2004, part III).

Broadly speaking, there are two ways in which we can understand anchoring to be at work in our engagement with virtual environments. In the first way, digital games and training simulations often reference and mimic actual anchorings in the attempt to make the purposes and objectives of virtual activities and interactions intuitively accessible for us. Consequently, some of the values and ideas that guide and constrain our beliefs and behaviours in the actual world are to some degree reproduced in virtual environments. For example, the notion that every single human life is invaluable implicitly underpins the success criteria of surgical training simulations and flight simulators. Another example of actual anchoring being used in virtual environments and activities is evident in the narrative setup of a variety of digital games, 
where the freedom and the safety of the (fictional) people that our avatars care for are presented as values worth fighting for (and also worth playing for).

Secondly, in contrast to our existence in the actual world, our accessing of virtual environments (and virtual subjectivities) allows us to exist in a world in which meaning and value is unambiguously established, objectified in computer code, and measured according to quantifiable metrics. In particular, commercial digital games tend to explicitly present unambiguous and resource-oriented world-views for their players. The clear and quantifiable objectives of those world-views are designed with the intention of fostering feelings of meaningful progress in their players, and to alleviate their existential anxiety (Gualeni, 2015, pp. 76-78, 128; Gualeni \& Vella, 2020, pp. 14, 82). Moreover, although activities within digital games are often autotelic and self-contained, they can achieve additional existential relevance as (and through) social performances, for example when these experiences feature social media components. In those cases, digital games can effectively become contexts in which players can attain various kinds of external validation for their in-game behaviour and selfrepresentation. The communities forming in and around digital games also constitute an influential component of social validation to the already existentially alluring possibilities offered by those virtual environments.

The possibility to achieve a sense of self-realization in virtual environments does not, however, only emerge from pre-designed mechanisms meant to motivate users with clear reward mechanisms. Their existential effects are, in other words, not limited to validating users for executing a certain set of actions or for taking ethical decisions of a specific kind. Virtual environments disclose opportunities to projectually re-construct and aesthetically fashion one's (virtual) self in a number of ways, some of which are intended by the designers of the virtual environment in question, while some others are independently devised and adopted by the users. For instance, players can achieve a sense of self-realization and existential anchoring in pursuing goals and activities that are materially inscribed in Super Mario Bros (Nintendo Creative Department, 1985) by defeating the evil Bowser and rescuing his captive, Princess Peach. The game mechanically and narratively invites that very course of action. On top of that, Super Mario Bros also grants points for killing enemies and positively rewards players for collecting the coins scattered throughout Mushroom Kingdom.

However, when interactively engaging with the virtual environment of Super Mario Bros., we are not constitutively bound to mindlessly pursue those objectives. Instead, we can treat the game as a tool to reflect on our beliefs and our conduct. With that critical attitude, we can decide to play Super Mario Bros. in accordance with deliberate, personal projects (see 
Gualeni, 2014; Westerlaken, 2017). An example of this alternative existential approach would be to carry out the decision to completely avoid collecting any coins while playing the game. Acting in this way can be considered a practice of self-fashioning when voluntarily taken as a way to keep oneself aware of how Super Mario Bros. is ideologically rooted in instrumental rationality (i.e. that the in-game goals invite and reward activities such as the accumulation of resources and the optimization of tasks).

Broadly speaking, existential anchorings in virtual worlds, and the kinds of selffashioning and self-realization that they offer, are not only quicker and less resistant to change than their actual counterparts, but are also not bound by several of the limitations that characterize everyday existence (Gualeni, 2015, pp. 76-78, 128; Gualeni \& Vella, 2020, p. 14, 82). Unlike our everyday life, our virtual projects do not need to be serious, permanent, determined by biological and cultural factors, or tied to the physical behaviours of the actual world. In short, we might claim that at least part of the existential attraction of virtual worlds lies in their capacity to offer us virtual anchorings that require less in terms of commitment, and that are less limited, than our 'actual' anchorings.

\section{Third category: Distraction}

In the previous section, we argued that virtual environments can disclose opportunities to pursue virtual projects of different kinds and to existentially anchor ourselves in them. Having previously discussed techniques for isolation, it should be evident that not all the relationships we can establish with virtual environments are necessarily meaningful in terms of existential self-realization. Similarly to isolation, 'distraction' techniques are existentially relevant not in their contributing to the construction of our 'self', but in their capability for momentarily cutting us off from meaninglessness and despair.

For the sake of clarity, we want to highlight a conceptual difference between the functioning of the repressing mechanisms belonging to the 'isolation' category and the ones that can be grouped under the 'distraction' label. Whereas the 'distraction' techniques aim at diverting the subject's attention from situations that might cause troubling thoughts and feelings, the 'isolation' ones attempt to re-frame those situations as something that can be considered not tragic, not disturbing, or not personally affecting us (and thus negligible). What follows is that if we decided to analyse digital games as tools for 'distraction', we would likely focus on their capability to capture and redirect their players' attention. If, on the other hand, we were to approach digital games as technologies for 'isolation', we would concentrate on 
how their virtual environments invite and foster a playful, unserious attitude towards troubling ideas and themes.

In 'The Last Messiah', Zapffe describes 'distraction' as a mode of protection by which one stunts one's awareness by 'constantly enthralling it with impressions. This is typical even in childhood; without distraction, the child is also insufferable to itself' (Zapffe 2004, part III). For Zapffe, the re-direction of the subject's attention from situations that might cause troubling thoughts and feelings is particularly prominent in the lifestyle of high society.

Distraction mechanisms play an obvious and obviously central role in our relationship with virtual environments and with digital games in particular. We often and explicitly approach digital games (especially in the 'casual' sector of the games industry) for distraction purposes, busying ourselves with relatively simple and tantalizing virtual objectives and activities that are typically brief and meant to provide constant stimulation. Indeed, such distraction could even be understood as the other side of the coin of the anchoring functions of games: we can distract ourselves from the lack of anchorings for our actual existence by taking on virtual re-anchorings.

For completeness, we want to point out that the dual effect of both distracting players and offering them possibilities for self-realization through anchoring is not exclusive to digital games in the 'casual' sector. Adventure and exploration games, especially when characterized by role-playing elements, are typically developed, promoted, sold, and consumed with the explicit objective of interactively disclosing the experience of being someone or something else: to develop that version of oneself in extraordinary ways, often under the promise of spectacular successes. Those games offer their players forms of escapism that are not merely distracting, but that clearly have existential 'anchoring' effects.

\section{Fourth category: Sublimation}

Zapffe considered 'sublimation' the rarest of the four survival mechanisms. The characteristic setting it apart from the other three categories is the fact that sublimation does not aim to repress cosmic panic, but rather to transform it into something that is perceived as meaningful. According to Zapffe '[t]hrough stylistic or artistic gifts can the very pain of living at times be converted into valuable experiences' (Zapffe, 2004, part III). In other words, sublimation is also a generative mechanism, and not simply a protective one. Zapffe exemplifies his idea of sublimation with the very activity of his own writing of 'The Last 
Messiah.' Through his text, his existential anxiety stops being a private and sterile struggle, but becomes something that can be shared with others, something that can inspire and uplift.

We argue that it is no great leap to consider a game like Every Day the Same Dream (Molleindustria, 2009) to be an analogous attempt at sublimation. The game depicts a lived experience - that of the alienated office worker in a late capitalist Western society - that might well give rise to existential panic, thanks to its repetition of an unfulfilling routine that appears to hold no meaning or potential for self-development. However, the very act of engaging with such an existence through rendering it in an expressive form already suggests the possibility of sublimating this existential panic. Of course, this suggestion presupposes both an inherent existential value to creative practices (à la Nietzsche), and an understanding of digital games as constituting a distinct, ludic form of artistic expression, that gives rise to a distinct kind of aesthetic experience (Vella, 2016b; Nguyen, 2020).

The notion that digital games can carry various forms of meaning is firmly established in game studies through notions such as that of 'procedural rhetoric' (Bogost, 2009). So is the idea that games can influence the player's existence, as in the idea of 'transformational play' (Barab et al, 2010) - or even that of the game designer through the creative design process itself (Gualeni, 2014; Gualeni \& Maureira, 2018). However, the chiefly instrumental perspective of these approaches - which frame digital games in terms of their capacity to impart particular skills or change specific beliefs, attitudes, and behaviours - diverges from Zapffe's existential drive. Closer to the mark, arguably, is the idea we have already identified in the first section of this paper as being central to existential ludology: all games echo the general existential structures of our being-in-the-world. By this understanding, when creating games, the designers frame their thoughts, feelings and beliefs in an interactive, ludic form. Symmetrically, when playing games, players are invited to bring before their consciousness the awareness of the existential structures of their own being.

\section{Conclusions}

In this chapter, we have tried to offer a perspective on how virtual environments could be understood as fundamentally contributing to our individual existence. The originality of our proposition chiefly consists in the fact that we did not articulate ways for understanding digital interactions and virtual worlds as novel routes to self-understanding and self-realization. What we have tried to do, instead, is to look at experiences and interactions in the virtual as activities 
that can assist us in coping with the lack of meaning that inherently characterizes human existence from the perspective of existential philosophy.

In the pursuit of this goal, we adopted Zapffe's categorization and used it as a conceptual lens to look at digital games. Our work revealed that there are indeed many ways in which virtual interactions can be, and in several ways already are, involved in protecting ourselves from acknowledging the inherent absurdity of our existence. Of course, as we already pointed out at the start of this chapter, the philosophical traditions Zapffe is drawing from, and the existential malaises he identifies, are those of the liberal, humanist Western subject. Zapffe adopts, and follows to its final consequences, a view of the subject as a solitary being, alienated from all sources of meaning outside themselves. His is a refiguration of the isolated, suffering genius of Romanticism, the disaffected bourgeois subject, or the destabilised Modernist subject adrift in a world in which systems of meaning have crumbled. To consider the virtual worlds of digital games as, on some levels, a response to the existential despair of such a subject, then, is to consider them as the response to a problem that has its roots in a distinctly European understanding of the self.

In these concluding passages, and very much in the vein of Zapffe's philosophical style, we would like to supplement the observations offered in this chapter with a cautionary note borrowed from the philosophy of technology.

It is hardly ever the case that a technology can be understood as a straightforward solution to a problem. With their adoption and integration within socio-technical contexts, technologies eventually become part of our lived experience and of our worldviews: at that point, technologies can be understood as co-constituting who we are, as participating in our self-understanding, as influencing the ways in which we relate to other people, and as participating in understanding and changing the worlds that we inhabit. Consequently, new technical solutions produce socio-technical effects that frequently extend well beyond their intended outcomes and modes of use, and bring about new problems and dissatisfactions. In his 1964 book Understanding Media: The Extensions of Man, Marshall McLuhan similarly observed that technology not only enhances human capabilities for thought and action, but it is also a form of self-amputation: new ways of establishing relationships with reality through media necessarily entail a balance between the increase in acuity of certain cognitive functions and the desensitization of others (McLuhan, 1964). In light of these observations, the existential use of virtual environments and interactions might be better understood not only as a new, helpful set of existential tools but (to use Zapffe's own words) also as 'a menace to our own well-being' (Zapffe, 2004, part II). 
What we are arguing here is that, while offering existential mechanisms that can promote our survival and well-being, our interactions with virtual environments can also be understood as contributing to making our species even less fit for life than it already is (see chapter 6). Among the other frequently discussed effects of being in virtual environments that are generally considered negative or not socially desirable are its making us less capable of concentration and deep reasoning (see Carr, 2011), and its potentially giving rise to phenomena such as addiction, derealisation, and solipsistic retreating within oneself (Plusquellec 2000). In other words, and as a more general kind of concluding statement, we argue that virtual environments are better understood existentially as technologies that influence the way we live our lives, and attribute meaning to them in both allowing us to transcend some aspects of our everyday relationship with the actual world, and in disclosing new ways in which our incompleteness, our pain, and our being unfit for life can be experienced and understood.

\section{References}

Barab, S.A., Gresalfi, M., \& Ingram-Goble, A. (2010). Transformational play: Using games to position person, content, and context. Educational Researcher, 39(7), 525-536.

Carr, N. (2011). The shallows: What the Internet is doing to our brains. New York, NY: WW Norton \& Company.

De Mul, J. (2009). Awesome technologies. Art and Social Change. International Yearbook of Aesthetics, 13, 120-139.

Fraina, J. (2010). Is it time? [Windows]. Digital game. https://jaimefraina.com/2010/01/is-it$\underline{\text { timel }}$

Gualeni, S. (2014). Freer Than We Think: Game Design as a Liberation Practice. Proceedings of the 2014 Philosophy of Computer Games conference. Bilgi University, Istanbul, Turkey: November 13-16.

Gualeni, S. (2015). Virtual Worlds as Philosophical Tools. Basingstoke: Palgrave Macmillan. Gualeni, S. \& Gómez Maureira, M. (2018). Self-Transformative effects of designing videogames and the challenge of capturing them quantitatively: a case study'. Proceedings of the 2018 Foundation of Digital Games Conference (Malmö, Sweden).

Gualeni, S. \& Vella, D. (2020). Virtual Existentialism: Meaning and Subjectivity in Virtual Worlds. Basingstoke, UK: Palgrave Pivot.

Gutman, M.L.H. \& Hutton, P.H. (Eds.) (1988). Technologies of the Self: A Seminar with Michel Foucault. London: Tavistock Publications. 
Kania, M.M. (2017). Perspectives of the Avatar: Sketching the Existential Aesthetics of

Digital Games. Wrocław (Poland): University of Lower Silesia Press.

Kirkpatrick, G. (2011). Aesthetic Theory and the Videogame. Manchester: Manchester University Press.

Leino, O.T. (2009). Understanding Games as Played: Sketch for a First-Person Perspective for Computer Game Analysis. Proceedings of the Philosophy of Computer Games Conference 2009. Oslo, Norway: August 13-15.

Leino, O.T. (2010). Emotions in Play: On the Constitution of Emotion in Solitary Computer Game Play. Doctoral dissertation. IT University of Copenhagen, Denmark.

Lionhead Studios (2004). Fable [Xbox]. Xbox Game Studios.

Lionhead Studios (2013). Fable III [Xbox360]. Xbox Game Studios.

Majkowski, T.Z. (2014). Freedom of Destruction and Carnivalesque in Video Games. Proceedings of the 8th International Conference on the Philosophy of Computer Games. Bilgi University, Istanbul, Turkey: November 13-16.

McLuhan, M. (1994). Understanding Media: The Extensions of Man. Cambridge, MA: MIT Press.

Molleindustria (2009). Every Day the Same Dream [PC]. Molleindustria.

Möring, S. (2014). Freedom in Games: Between Fear and Boredom. Proceedings of the 8th International Conference on the Philosophy of Computer Games. Bilgi University, Istanbul, Turkey: November 13-16.

Möring, S. \& Leino, O.T. (2016). Beyond Games as Political Education: Neo-Liberalism in the Contemporary Computer Game Form. Journal of Gaming and Virtual Worlds, 8(2), 145161.

Mukherjee, S. (2009). Remembering How You Died: Memory, Death and Temporality in Videogames. Proceedings of DiGRA 2009 - Breaking New Ground: Innovation in Games, Play, Practice and Theory. London, UK: September 1-4.

Nguyen, C.T. (2020) (forthcoming). Games: Agency as Art. New York, NY: Oxford University Press.

Nintendo Creative Department (1985). Super Mario Bros [Nintendo Entertainment System]. Nintendo.

Payne, M.T. (2008). Interpreting Gameplay Through Existential Ludology. In Richard E. Ferdig (Ed.). Handbook of Research on Effective Electronic Gaming in Education (pp. 621635). Hershey, PA: Information Science Reference. 
Plusquellec, M. (2000). Are virtual worlds a threat to the mental health of children and adolescents? Archives de pediatrie: organe officiel de la Societe francaise de pediatrie, 7(2), 209-210.

Sartre, J.P. (1943). Being and Nothingness. New York, NY: Washington Square Press.

Sophocles (1984). The Three Theban Plays - Antigone, Oedipus King, Oedipus at Colonus (trans. by R. Fages). New York, NY: Penguin Classics.

Vella, D. (2015). The Ludic Subject and the Ludic Self: Analyzing the 'I-in-the-Gameworld'. Doctoral dissertation: IT University of Copenhagen, Denmark.

Vella, D. (2016a). Who am "I" in the Game?': A Typology of Modes of Ludic Subjectivity. Proceedings of the 1st Joint International Conference of DiGRA and FDG. Dundee, Scotland: August, 1-6.

Vella, D. (2016b). The Ludic Muse: The Form of Games as Art. Countertext, 2(1), 66-84.

Vella, D. \& Gualeni, S. (2019). Virtual Subjectivity: Existence and Projectuality in Virtual Worlds'. Techne': Research in Philosophy of Technology, 23(2).

Westerlaken, M. (2017). Self-fashioning in action: Zelda's Breath of the Wild Vegan Run. In Philosophy of Computer Games Conference. Krakow, Poland: November 28 - December 1 Zapffe, P.W. (2004) (1933). The Last Messiah (trans. by G.R. Tangenes). Philosophy Now, 45. Zapffe, P.W. (1996) (1941). Om det Tragiske [On the Tragic]. Oslo: Pax forlag. 